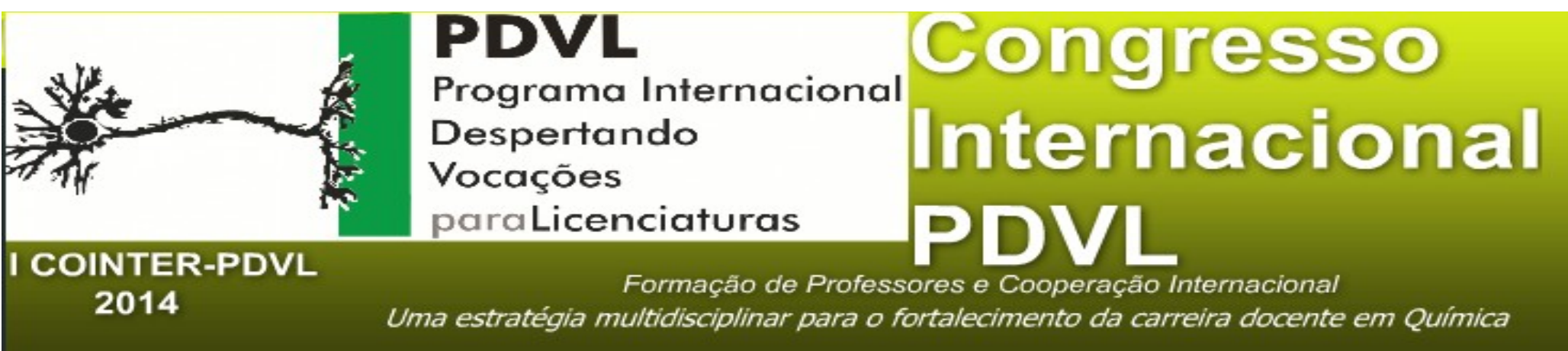

\title{
INOVAÇÃO NO ENSINO DE QUIMICA A PARTIR DE PROPOSTAS METODOLOGICAS DIFERENCIADAS
}

Apresentação: Pôster

\begin{abstract}
Mayrane Carla Marques do Nascimentoㄹ; Sarah Kelly Melo Cavalcante ${ }^{2}$; Etelino Feijó de Melo ${ }^{3}$; Johnnatan Duarte de Freitas ${ }^{4}$
\end{abstract}

\section{Resumo}

Neste trabalho serão abordadas questões teóricas e metodológicas no ensino de química com enfoque na importância do Programa Institucional de Bolsas de Iniciação à Docência - PIBID no processo de ensino e aprendizagem para a concretização de atividades experimentais e extracurriculares desenvolvidas em uma escola de educação básica. Priorizou-se o desenvolvimento de propostas metodológicas diferenciadas, como o uso de aulas experimentais e atividades lúdicas, como alternativas para tornar a aprendizagem de química mais significativa. Nessa perspectiva, foram realizadas ações numa escola da rede pública estadual de ensino, situada município de Maceió-AL. Buscou-se aprimorar o modo habitual como a disciplina de química vem sendo abordada em sala de aula, a partir de novas possibilidades de práticas de ensino para que os alunos

1Licenciatura em Química/Instituto Federal de Alagoas (IFAL) / Programa Institucional de Bolsa de Iniciação à Docência - PIBID / mayrane.carla@hotmail.com 22Licenciatura em Química/ Instituto Federal de Alagoas (IFAL) / Programa Institucional de Bolsas de Iniciação à Docência/sarahkmcavalcante@hotmail.com em Química / Instituto Federal de Alagoas (IFAL) / Programa de Extensão Internacional Despertando Vocações para as Licenciaturas - PDVL / etelino@gmail.com

${ }^{4}$ Doutor em Química / Instituto Federal de Alagoas (IFAL) / Programa de Extensão Internacional Despertando Vocações para as Licenciaturas - PDVL / Programa Institucional de Bolsa de Iniciação à Docência - PIBID/ johnnatan.duarte@ifal.edu.br 
obtenham aprendizagens significativas. As metodologias utilizadas mostraram-se relevante no que concerne ao ensino pois conseguiu-se estimular os alunos da escola ao estudo da disciplina de química.

Palavras-Chave: Ensino. Química. Metodologia. Inovação

\section{Introdução}

É notório que nos dias atuais vem se tornando cada vez mais frequentes pesquisas acerca de metodologias que possam aprimorar o processo de ensino aprendizagem em química.

Muitos estudiosos vêm discutindo a favor de um ensino mais instigante que busque aprendizagens significativas. Um dos processos mais relevantes tem sido a importância da relação teoria e prática no processo de ensino aprendizagem dos alunos.

Buscou-se aprimorar o modo habitual como a disciplina de química vem sendo abordada em sala de aula, a partir de novas possibilidades de práticas de ensino para que os alunos obtenham aprendizagens significativas.

Dessa forma, ficará clara a relevância de refletirmos acerca da necessidade de trabalhar metodologias que fogem do ensino tradicional.

\section{Fundamentação teórica}

As metas do sistema educacional nos últimos anos, vêm contribuindo de maneira significativa para melhoria do processo de ensino aprendizagem. No entanto, para que entendamos o quanto as nossas escolas estão melhorando é preciso que seja refletido acerca do ensino em décadas passadas.

Em décadas passadas os professores se planejavam a partir de práticas metodológicas meramente técnicas. Com relação à educação tecnicista, Saviani (1984, p.16) traz que a:

[...] proliferação de propostas pedagógicas tais como o enfoque sistêmico, o micro-ensino, o tele-ensino, a instrução programada, as máquinas de ensinar etc. Daí, também, o parcelamento do trabalho pedagógico com a especialização de funções, postulando-se a introdução no sistema de ensino de técnicos dos mais diferentes matizes. Daí, enfim, a padronização do sistema de ensino a partir de esquemas de planejamento previamente formulados aos quais devem se ajustar as diferentes modalidades de disciplinas e práticas pedagógicas.

O que se tem percebido a muitos anos, é que alguns professores agem igualmente aos 
professores da época retratada. Mas, em meados do século XX, novas teorias surgem no Brasil dando-se ênfase psicologia educacional. Uma dessas novas teorias é a do ensino construtivista, e de acordo com Mario Carretero (1997) construtivismo:

\footnotetext{
É a ideia que sustenta que o indivíduo - tanto nos aspectos cognitivos, sociais e afetivos - não é um mero produto do ambiente nem um simples resultado de suas disposições internas, mas, sim, uma construção própria que vai se produzindo, dia a dia, como resultado da interação entre esses dois fatores. Em consequência, segundo a posição construtivista, o conhecimento não é uma cópia da realidade, mas, sim, uma construção do ser humano.
}

A partir do que nos traz Bonito (2008) a concepção construtivista do ensino e da aprendizagem parte da constatação de que a escola torna acessível aos alunos aspectos da cultura humana (cognitivos, psicomotores, sócio afetivos. Solomon (1994) nos retrata que o construtivismo é um reescrever as ideias dos alunos.

De acordo com o que nos traz Marco Antônio (2010) a aprendizagem é dita significativa quando uma nova informação (conceito, ideia, proposição) adquire significados para o aprendiz através de uma de uma espécie de ancoragem em aspectos relevantes da estrutura cognitiva préexistente do indivíduo.

No que concerne à disciplina de química é sabido que em muitas situações em sala de aula a relação da disciplina de química com o dia a dia dos alunos não é explicitamente abordada por inúmeros professores, no entanto, afirma-nos Brown et al. (2005, p. 2), que a química é “[...] uma ciência extremamente prática que tem grande impacto no dia a dia.

Compreende-se que a partir das muitas discussões com o objetivo de redefinir as formas de ensinar, foram surgindo diferentes estratégias de ensino que funcionam como mediadoras de aprendizagens significativas.

\section{Metodologia}

O trabalho realizado teve caráter qualitativo na qual foi observado o comportamento dos alunos perante a aplicação das atividades que fugiam de certa forma da realidade da aula convencional.

As atividades aplicadas foram aulas experimentais e jogos didáticos. Essas aplicações foram realizadas no decorrer de dois anos e meio, tendo em vista ter sido o período de lotação de alunos bolsistas do PIBID na escola participantes. 
Para análise de cada aula experimental e jogo didático aplicados foram submetidos aos alunos questionários semiestruturados a fim de que para que se pudesse averiguar a opinião dos mesmos no que se refere a metodologia aplicada. Os questionários realizados foram: Você gosta da disciplina de química? Você acha que o uso de as aulas experimentais e jogos didáticos nas aulas de química podem contribuir para aprendizagem em química? Qual a relação professor-aluno durante as aulas de química? Você queriam que os professores utilizassem outras metodologias?

\section{Resultados e Discussões}

Os questionários foram aplicados antes e depois da realização das atividades. Inicialmente quando perguntado se os alunos gostavam de química, quase todos os alunos responderam que não. Os alunos relataram ainda, que não conseguiam compreender a importância dos conteúdos da disciplina para o dia a dia deles.

Quando indagado se o uso de aulas experimentais e jogos didáticos poderiam contribuir para a aprendizagem deles em química, a maioria dos alunos afirmaram que não sabiam responder tendo em vista os professores da escola não trabalharem com esses tipos de atividades em sala de aula.

Ressaltaram ainda, que a relação com os professores era normal, mas que eles desejavam mesmo, aulas mais dinâmicas, pois da maneira como os conteúdos eram passados eles não conseguiam compreender.

Quando perguntado se eles queriam que os professores usassem as metodologias citadas anteriormente os alunos responderam que sim, pois eles achavam as aulas chatas, mas se os professores mudassem a forma de trabalhar os conteúdos de química, a disciplina poderia ficar mais interessante.

Posteriormente a aplicação das atividades, os alunos ressaltaram que a partir das práticas eles conseguiram visualizar os conteúdos explicados pelo professor. Que através de aula experimental e dos jogos as aulas eram mais divertidas e que eles aprenderam mais fácil. Verificouse com a fala da maioria dos alunos que os mesmos queriam dizer que a partir das aulas experimentais e dos jogos eles poderiam fazer perguntas e as respostas serviriam de conceitos a serem trabalhos.

No caso da relação professor aluno os alunos disseram que a partir de atividades diferentes eles conseguem ter mais contato com os mesmos, pois dessa forma, eles sentem-se mais a vontade para fazer perguntas. 
Os alunos afirmaram que as metodologias contribuíram para aprendizagem deles, que as aulas se tornaram mais instigantes e que eles passaram a ter mais vontade de assisti-las.

Enfim, a partir das aulas experimentais e dos jogos foi percebido que os alunos necessitam de metodologias mais instigantes que busquem trabalhar os conteúdos com dinamismo, prendendo ao máximo a atenção dos alunos no que concerne a aprendizagem.

As figuras 1 e 2, representam duas turmas, uma realizando um aula experimental alternativa e a outra, uma turma jogando um dos jogos desenvolvido.

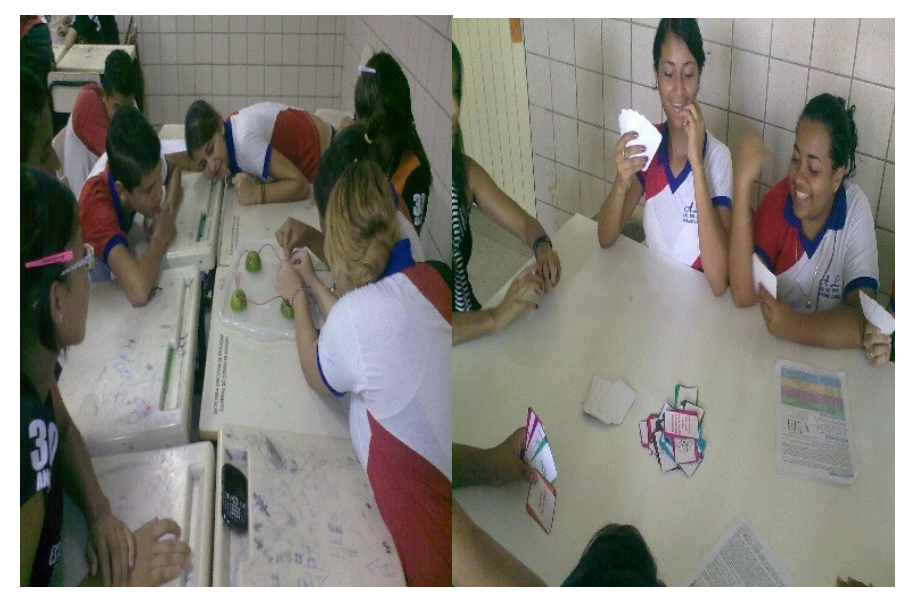

Figuras 1 e 2: Turmas do Ensino médio participante do experimento e Jogando Quimassa. Fonte: própria

\section{Conclusões}

É provado, o quão se torna relevante o processo de ensino aprendizagem quando os estudantes são oportunizados a vivenciar diferentes ferramentas metodológicas enquanto recursos de ensino. A partir das experiências aqui compartilhadas, é fundamental que os profissionais da educação reflitam sobre a necessidade de serem repensadas e reorganizadas as práticas trabalhadas em sala de aula.

Faz-se necessário que sejam realizadas discussões de conteúdos em sala de aula a partir dos conhecimentos preexistentes dos alunos. Pois, a partir do senso comum, conceitos são reconstruídos de modo que é proporcionada a real compreensão de mundo e qualidade de vida a partir dos conhecimentos químicos.

\section{Referências}

BONITO. Jorge. 2008. Perspectivas atuais sobre o ensino das ciências: clarificação de caminhos. Terra e Didática, 4(1):28-42http://www.ige.unicamp.br/terraedidatica/ 
BROWN, T. L.; LEMEY Jr, H. E.; BURTEN, B. E. e BURDGE, J. R. Química: a ciência central. 9a ed. São Paulo: Pearson Prentice Hall, 2005.

CARRETERO, Mario. Construir e Ensinar as Ciências Sociais/hist. São Paulo: Artmed, 1997.

MOREIRA, Marco Antônio. Mapas conceituais e aprendizagem significativa. São Paulo: Centauro Editora, 2010.

SAVIANI, Dermeval. Escola e democracia: teorias da educação: curvatura da vara: onze teses sobre educação e política. 5.ed. São Paulo: Cortez/Autores Associados, 1984. (Coleção Polêmica do nosso tempo, 5).

SOLOMON, J. (1994).The Rise and Fall of the constructivism. Studies in Science Education, 23: 119. 